Mal J Nutr 25(2): 273-285, 2019

\title{
Changes in energy and nutrient intakes among Malaysian adults: findings from the Malaysian Adult Nutrition Survey (MANS) 2003 and 2014
}

\author{
Ahmad Ali Zainuddin ${ }^{1,2}$, Norazmir Md. Nor ${ }^{1 *}$, Safiah Md Yusof ${ }^{3}$, Adriana Irawati \\ Nur Ibrahim ${ }^{4}$, Tahir Aris ${ }^{1} \&$ Foo Leng Huat $^{5}$ \\ ${ }^{1}$ Universiti Teknologi MARA, Puncak Alam; ${ }^{2}$ Institute for Public Health, Ministry of \\ Health Malaysia, Kuala Lumpur; ${ }^{3}$ International Medical University, Kuala Lumpur; \\ ${ }^{4}$ Universiti of Malaya, Kuala Lumpur; ${ }^{5}$ Universiti Sains Malaysia, Kubang Kerian
}

\begin{abstract}
Introduction: Monitoring changes in energy and nutrient intakes of the population over the course of time is essential to help healthcare providers develop effective dietary policies. The aim of this study was to assess the changes in the nutrient intake and Recommended Nutrient Intake (RNI) achievements by using the data obtained from the Malaysian Adult Nutrition Surveys (MANS) that were carried out in 2003 and 2014. Mis-reporting of energy intake was taken into account. Methods: Dietary data were obtained from MANS 2003 and MANS 2014, which involved a combined total of 4,044 randomly selected respondents, aged 18-59 years, using a single 24-hour diet recall. Energy and nutrients calculations were based on the Malaysian Food Composition database using the Nutritionist Pro software. The results were compared against the RNI for Malaysia to assess dietary adequacy. Results: The proportions of calories derived from macronutrients were within the recommendations for a healthy diet. The consumption of protein, fat, calcium, iron and vitamin A was significantly higher in 2014 than in 2003. The consumption of protein, iron, vitamin C, and vitamin A was found to exceed the RNIs in 2014. However, carbohydrate and sodium intakes had significantly decreased. Despite the decrease, sodium intake still exceeded RNI recommendations. Conclusion: Signs of changing energy and nutrient intakes were found, including increases in protein and fat intakes since 2003, and decreased carbohydrates. This could be an alarming indicator of the tendency to eat energy dense food among the population.
\end{abstract}

Keywords: Nutrient intake, Malaysian population, 24-hours diet recall

\section{INTRODUCTION}

The estimation of nutrient intake is an essential component of monitoring nutritional status. It identifies groups which are nutritionally at risk due to insufficient or excessive intake of specific nutrients. In addition, it helps planners to target, plan and evaluate nutrition intervention programmes, and, to establish dietary recommendations, food regulations and nutrition policies (Sandström, 2001).

In Malaysia, the Ministry of Health carried out the Malaysian Adult Nutrition Survey (MANS), a cross-sectional survey that was conducted for the first time in 2003 on a representative sample of the Malaysian adult population. This survey

\footnotetext{
*Corresponding author: Norazmir Md Nor

Associate Professor, Centre of Nutrition and Dietetics, Faculty of Health Sciences

Universiti Teknologi MARA, 42300 Puncak Alam, Selangor, Malaysia

Tel: +6-03-3258 4510, +6019-666 4534; Fax: +6-03 3258 4599; Email: azmir2790@uitm.edu.my

doi: https://doi.org/10.31246/nutriweb-2018-0023
} 
allowed researchers to estimate the nutrient intake (Mirnalini et al., 2008), meal patterns (Manan et al., 2012), nutritional status (Azmi et al., 2009), physical activity (Poh et al., 2010), and use of dietary supplements $(\mathrm{MOH}$ Malaysia, 2008a). MANS also provided data for the food consumption database (MOH Malaysia, 2006).

The second MANS was carried out in 2014 and its results were published in three reports (IPH, 2014c; 2014b; 2014a). This second survey was undertaken to evaluate changes in dietary patterns and monitor the nutritional status of the Malaysian population, particularly with respect to the increasing prevalence of non-communicable diseases. The dietary patterns of the population may deviate from those indicated in MANS 2003 due to urbanisation and the recent increase in diet-related chronic diseases, both of which have resulted in rapid changes in dietary intakes among the Malaysian population (IPH, 2015). A comprehensive study on the energy and nutrient intakes of the Malaysian population would provide the additional information that could then be used to develop more effective food and nutrition policies.

While surveys on nutritional intakes are carried out regularly in various countries, several methodological problems are well known. These include the use of 24-hour dietary recalls and food frequencies in large-scale surveys. The mis-reporting of energy intakes (EIs) (both under and over-reporting) is a common problem encountered in a number of national surveys conducted among adults (Garriguet, 2008; Klesges, Eck \& Ray, 1995; Mackerras \& Rutishauser, 2005).

This study was conducted in order to assess changes in nutrient intake by comparing the survey data of 2014 to that of 2003. It also evaluated the current nutrient intake among the adult population in Malaysia using only reliable data on EI. The findings of this study should serve as a foundation for the formulation of dietary intervention programmes, educational projects, and nutritional guidelines for both healthcare providers and the general public.

\section{MATERIALS AND METHODS}

This study was approved by the Medical Research and Ethics Committee (MREC), Ministry of Health Malaysia [NMRR-17888-34549(IIR)].

\section{Sampling design and study population}

MANS was conducted by the Ministry of Health Malaysia. It consisted of a series of cross-sectional nutrition surveys representing non-institutionalised Malaysian adults aged 18-59 years old. The MANS data collected in 2003 involved 6,928 respondents $(3,523$ male and 3,405 female), and that in 2014 involved 2,973 respondents $(1,553$ male and 1,420 female). Each survey followed a stratified multistage sampling design. The surveys combined faceto-face interviews with anthropometry measurements. The large majority of respondents were interviewed and physical measurements were taken at their home. In a small number of cases, data were collected at their offices. The overall response rates for the survey were 94\% in 2003 (MOH Malaysia, 2008b) and 80\% in 2014 (IPH, 2014c). Informed consent was obtained from all participants. For the present study, analyses were restricted to adults who had a reliable, self-reported 24-hour diet recall (after excluding misreporting of EI) and had completed anthropometric measurements. This paper included a reanalysis of the data from the two studies mentioned.

\section{Socio-demographic and anthropometric characteristics}

The socio-demographic information of the respondents in this study referred to their gender (male-female) and strata (urban-rural) only. Anthropometric 
measurements included body weight and height. The reliability and validity of all these measurements are wellestablished (Baharudin et al., 2017; Geeta et al., 2009). Body mass index (BMI) was calculated as weight (in kilogram) divided by height (in meter squared). The BMI was used to estimate the basal metabolic rate (BMR) of the respondent. Mis-reporting of EI was determined based on the ratio of reported EI to estimated BMR, or EI:BMR.

\section{Dietary assessment}

Energy and nutrient intake were measured from a single 24-hour dietary recall. Trained nutritionists interviewed the subjects and collected detailed information on food items and the quantities consumed during the previous day. Where possible, food recipes were recorded. The interactive 24-hour dietary recall was conducted to assess all foods and drinks consumed by the respondent during the preceding 24hour period, included cooking methods, brand names and portion sizes.

Dietary assessment aids, such as an album of food pictures (IPH, 2011; $\mathrm{MOH}$ Malaysia, 2002) and household measures, were used to facilitate the identification of foods and quantification of portion sizes consumed. The album consisted of actual sized photographs of individual foods, which were useful in helping subjects estimate amounts eaten as fractions or multiples of the illustrated reference portions.

The dietary analysis software, Nutritionist Pro $^{\mathrm{TM}}$ Nutrition Analysis Software version 5.3 (Axxya Systems, 2014), was used for this study. For local complex mixed cooked dishes that were not available in any of the food databases, local recipe books were used to identify at least two recipes for each dish. For each recipe, it was ensured that the quantitative information on oils, fats and salt were available. The energy and nutrient content of these recipes were analysed using the Malaysian
Food Composition Tables (Tee et al., 1997) and the average of these values was entered into the Nutritionist Pro software. For example, two recipes for fish curry (gravy) were obtained and the ingredients were analysed for energy and nutrient values (per 100 gram). The average values of the two recipes were then used as the standard for nutrient content of fish curry. For processed and packaged foods, information on energy and nutrient content on their labels was entered into the software for analysis. For all foods consumed by the subjects, steps were taken to ensure that oils, fats and salt were accounted for. The macro- and micro-nutrient intakes that are reported in this paper are based exclusively on the consumption of food and fluids and do not include contributions from vitamin and mineral supplements.

\section{Mis-reporting of EI}

To estimate the mis-reporting of EI from the 24-hour diet recall, the ratio of reported total daily EI to BMR, or EI:BMR was calculated. The calculation for BMR for the Malaysian population was done using the predictive equation by Ismail et al. (1998). Respondents were classified as follows according to their EI:BMR ratio: under-reporters (EI:BMR< 1.2); plausible (EI:BMR 1.22.4); and over-reporters (EI:BMR >2.4) of EI, as suggested by Black (2000) and Goldberg et al. (1991). Other studies on the Malaysian population have also applied the cut-off points $<1.2$ and $>2.4$, to classify the under-and over-reporting of individuals (Sahathevan et al., 2015; Sharif, Wen \& Rajikan, 2016).

\section{Dietary adequacy}

The most recent version of Recommended Nutrient Intakes (RNI) for Malaysia (NCCFN, 2017) was used to assess dietary adequacy among Malaysian adults according to age, gender and physical activity level (PAL). For the general population group, a PAL score of 
1.6 (i.e. moderately active) was used for this study, as recommended.

The percent contribution of macronutrients towards total daily EI was considered achieved if the respondent's mean intake was within the following recommendations of the 2017 Malaysian RNI: $50-65 \%$ of energy from carbohydrate, $10-20 \%$ from protein and $25 \%$ to $30 \%$ from fat. For comparison, the previous 2005 Malaysian RNI guidelines had the following cut-offs: 55$70 \%$ of energy from carbohydrate, $10 \%$ to $15 \%$ from protein and $20-30 \%$ from fat. The adequacies of macronutrients (carbohydrate, protein, and fat) intake were compared between RNI 2005 and RNI 2017 by using the respective cutoff points for both years, in order to ascertain and analyse their differences.

For the adequacy of sodium intake, the 2017 Malaysian RNI for sodium of $1500 \mathrm{mg}$ per day for adults was compared to the World Health Organization (WHO) guidelines of 2012, which recommends a sodium intake of $<2000 \mathrm{mg}$ per day for adults.

\section{Statistical analysis}

Data on energy and nutrient intakes were transferred from the Nutritionist Pro to the Statistical Package for Social Sciences (SPSS) version 21.0 for statistical analysis. The total EI data of the respondents were converted to $z$-score to identify outliers. After identifying the outliers, all cases within normal range were selected and the rest discarded; this was to ensure the normality of the data.

The means and standard errors (SE) of the nutrient intake, as well as percentages meeting the RNI for selected nutrients were calculated. Student's $t$-test was performed to assess the significance of differences in mean intakes between the two study periods. For each nutrient, the findings were compared with the Malaysian RNIs for the respective groups. Subsequently, the average intake for both groups combined, gender (male-female) and strata (urban-rural) were determined. Statistical significance was accepted at $p<0.05$.

\section{RESULTS}

In this study, we found that underreporting of EI were $53.6 \%$ and $61 \%$ from MANS 2003 and MANS 2014, and 2.4\% and $1.7 \%$ of over-reporting, respectively.

\section{Changes in energy and macronutrient intakes}

Table 1 shows the comparison of energy and nutrients intake of MANS 2003 and MANS 2014. Based on the table, there are no significant changes in EI between the MANS in terms of gender and respondents from both groups. The same is also true for respondents from both urban and rural areas.

Table 2 shows the percentages of RNI achievement for subjects for both years. The mean percentage of RNI achievement for energy was significantly higher ( $p$ $=0.04)$ in the year $2014(100 \%$ RNI) than in 2003 (99\% RNI). There were no significant differences in the percentages of RNI achievement for EI in both gender groups. A significant increase $(p=0.03)$ in the percentage of RNI achievement for EI was noted among respondents in urban areas. In 2003, both strata showed similar trends in terms of EI. However, in 2014, there was a larger increase in the mean EI among urban respondents compared to rural respondents.

Figure 1 shows the mean percentages of energy obtained from the intake of the three macronutrients, carbohydrate, protein and fat. In 2003, the mean carbohydrate intake was $288 \mathrm{~g}$, which declined significantly to $273 \mathrm{~g}$ in 2014. This decline was observed among male, female, urban and rural populations. In 2003, carbohydrate intake contributed $57 \%$ to the total EI of the respondents, whereas in 2014 this value had decreased to $53 \%$. Overall, mean carbohydrate intakes were higher among males 


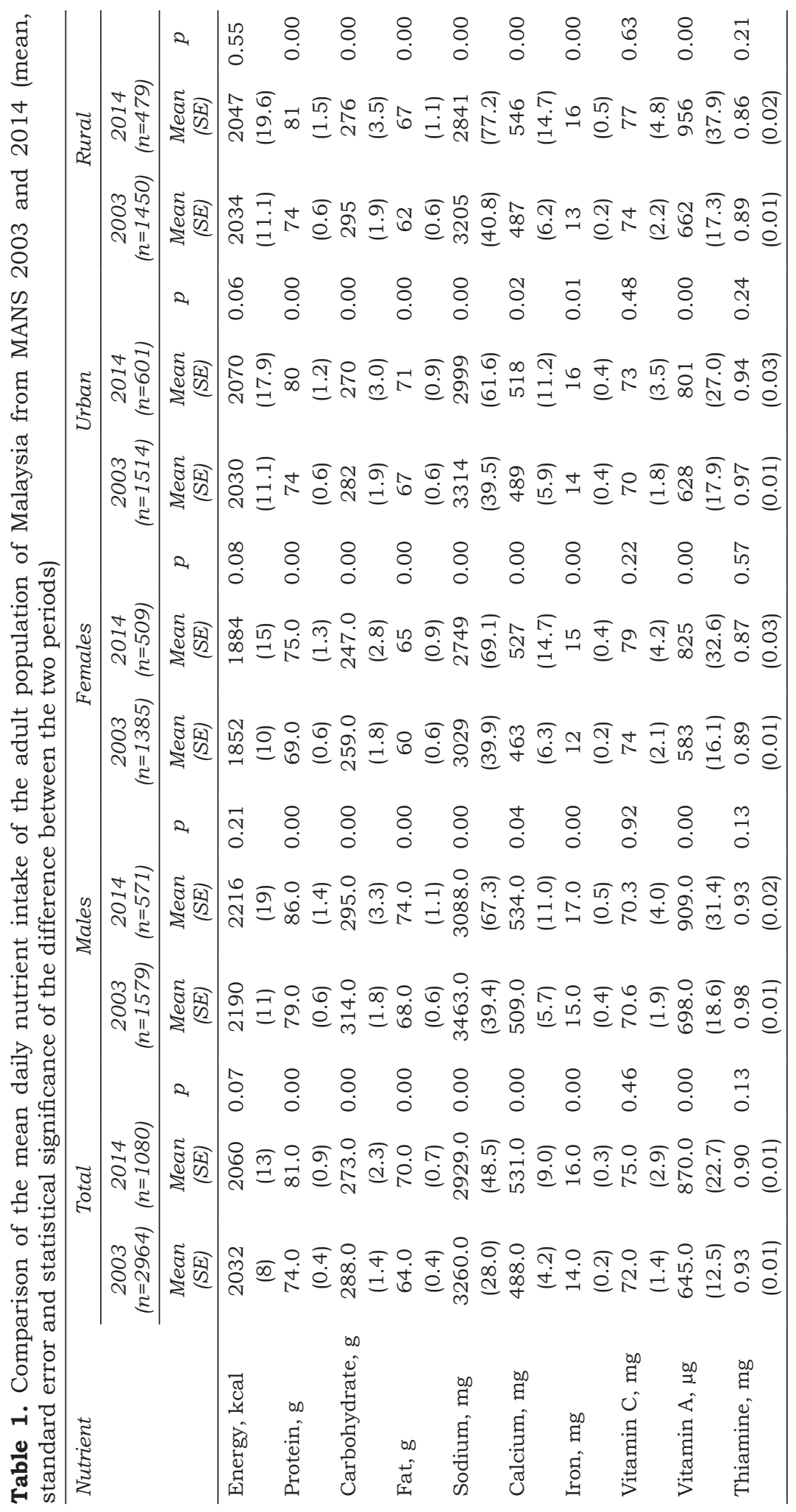




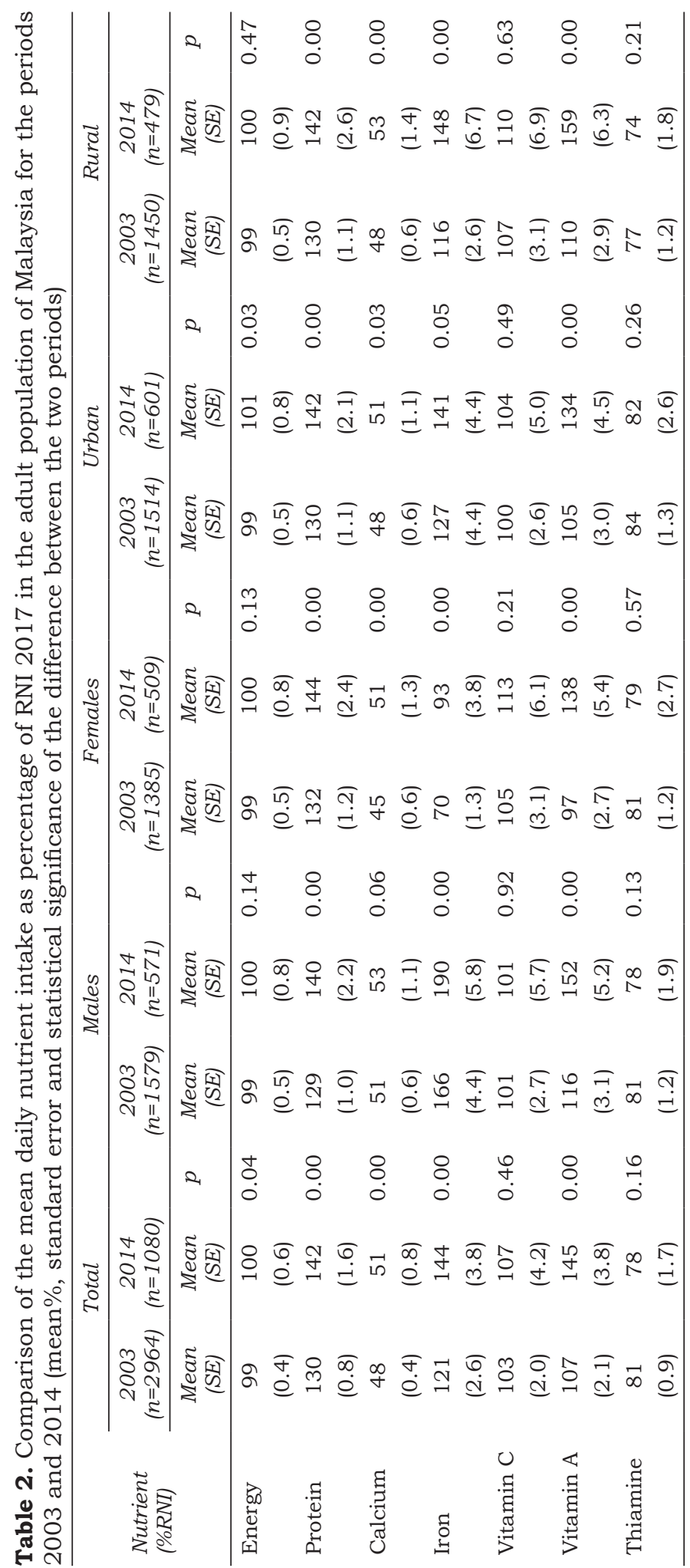




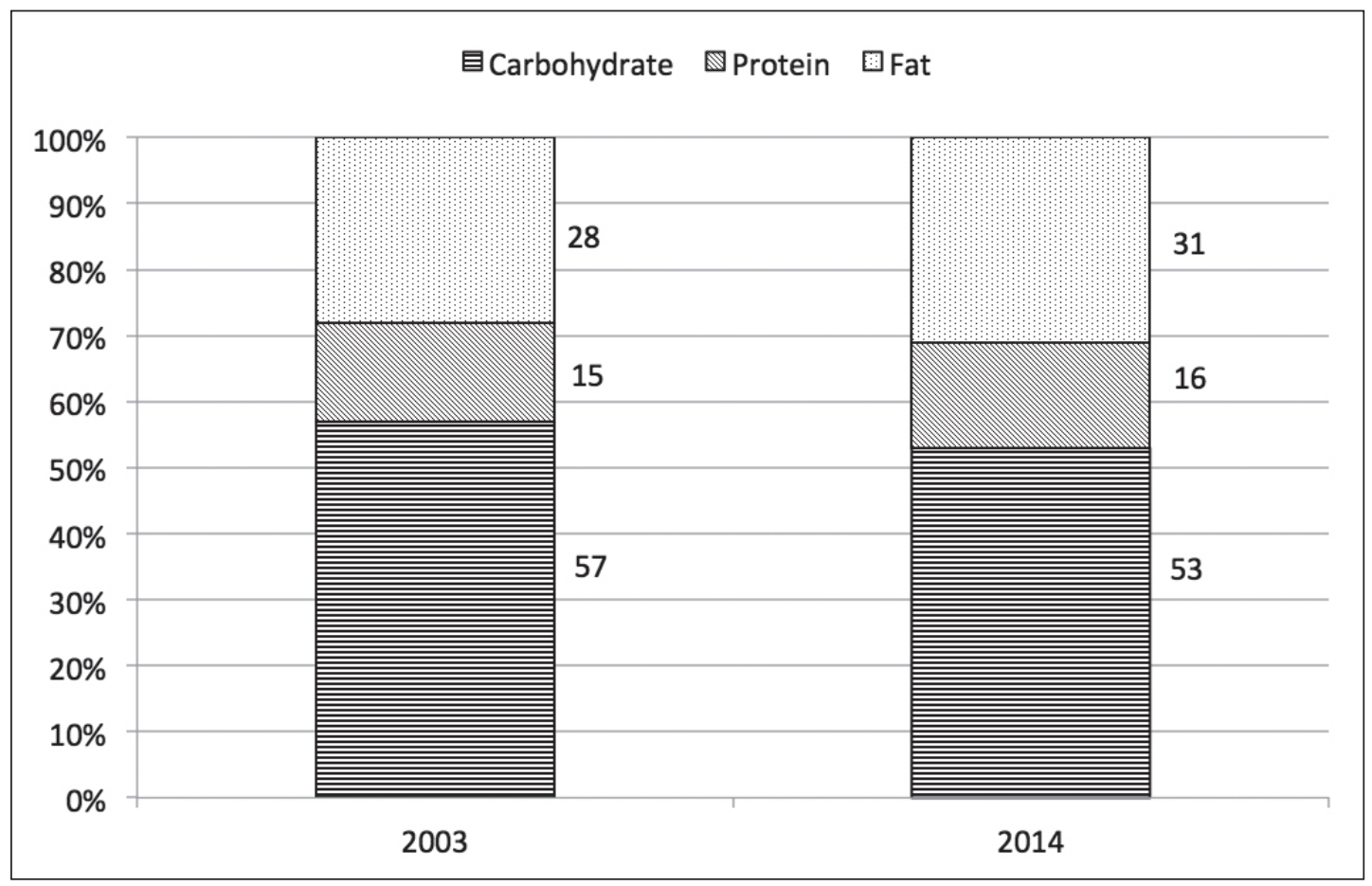

Figure 1: Mean percentages of energy obtained from macronutrient intake

than females. Rural adults had a higher carbohydrate intake than urban adults.

The mean protein intakes for 2003 and 2014 were $74 \mathrm{~g}$ (15\% of total EI) and $81 \mathrm{~g}$ (16\% of total EI), respectively. From 2003 to 2014, a significant increase in protein intake was observed among the male, female, rural, and urban populations. Both years showed high RNI achievements for protein intake (130\% in 2003 and 142\% in 2014).

The mean fat intake was significantly higher in $2014(70 \mathrm{~g}$ or $31 \%$ of total EI) than in 2003 (64 g or $28 \%$ of total EI). From 2003 to 2014, the fat intakes among the male, female, urban, and rural populations all showed an increasing trend. It is worth noting that the percentage increase in total energy obtained from fat intake coincides with the decline in the percentage of energy obtained from carbohydrates, implying that a portion of carbohydrate sources had been replaced by fat sources.
Table 3 shows the percentages of total respondents for both survey years who had met the adequate ranges of energy contribution from carbohydrate, protein, and fat. These percentages are all based on 2005 RNI cut-off values. In 2003, the percentages of respondents meeting the adequate range of energy contribution from carbohydrate, protein and fat were $55.3 \%, 52.1 \%$ and $49.1 \%$ respectively, whereas in 2014, the corresponding values were $36.2 \%, 43.2 \%$ and $39.0 \%$ respectively. However, the percentages for protein and fat decreased when RNI 2017 cut-off values were used (Table 4). In MANS 2014, a decrease in carbohydrate contribution to total EI (57\% to $53 \%$ ) was observed, concomitant with a rise in protein (15\% to $16 \%)$ and, fat $(28 \%$ to $31 \%)$ contribution to total EI compared to 2003 (Figure 1). Based on these findings, it is clear that the results obtained using 2017 RNI cut-off values do not reflect the results obtained using 2005 RNI cut-off values. 

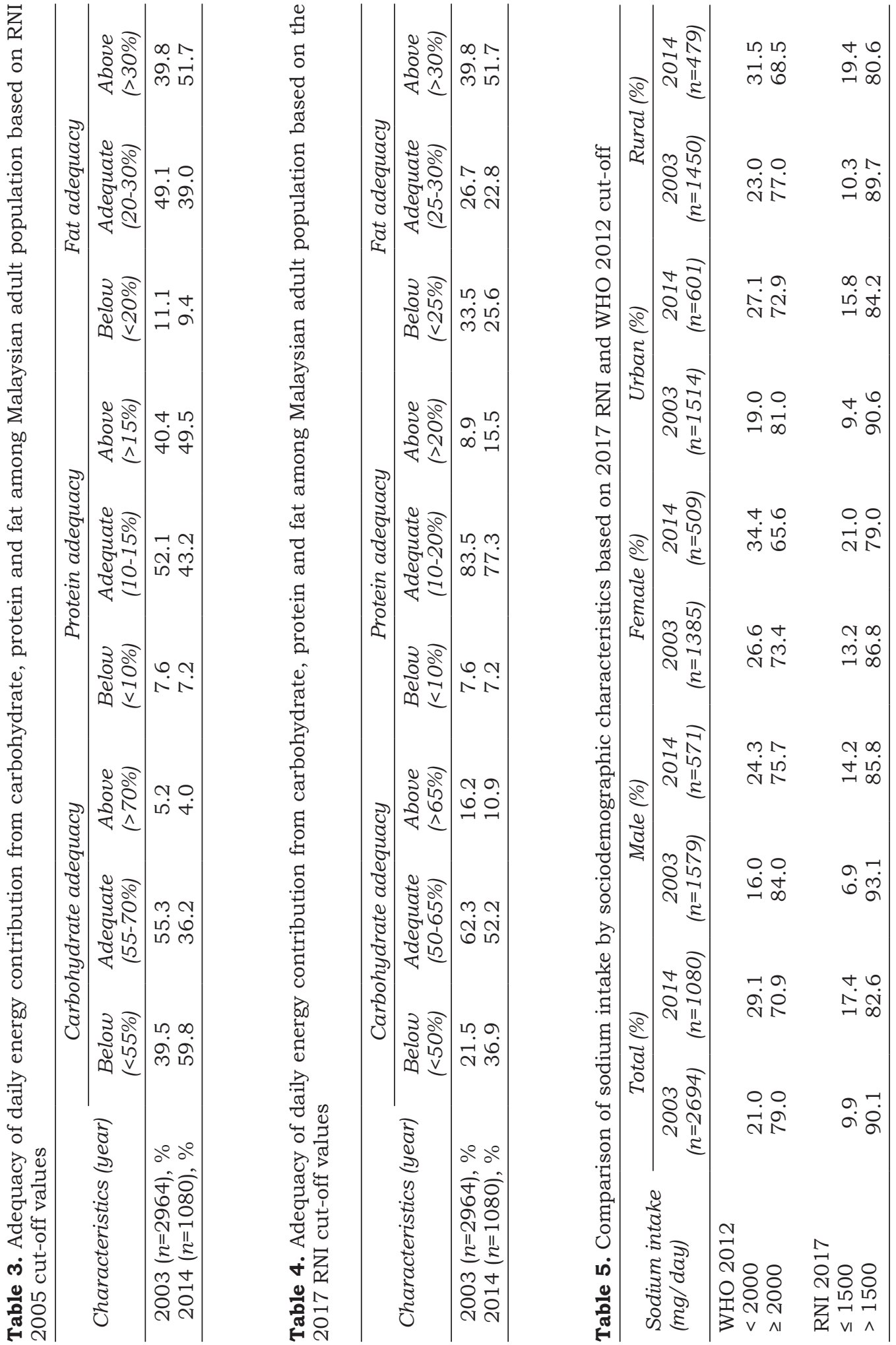


\section{Changes in micronutrient intake}

There is a significant increase $(p=0.00)$ in the mean intake of calcium from the year 2003 (488 $\mathrm{mg} ; 48 \%$ of RNI) to 2014 (531 mg or 52\% of RNI). Clearly, based on the 2017 RNI, calcium intake is inadequate. The mean intake of iron was $14 \mathrm{mg}$ in the year 2003 (121\% RNI) and $16 \mathrm{mg}$ in 2014 (144\% RNI). This showed that the mean intake of iron had significantly increased $(p=0.00)$ between 2003 and 2014. However, it should be pointed out that the increase in mean iron intake occurred largely among males. Even though there was an increase from 2003 to 2014, iron intake among females was still slightly below RNI in 2014. A significant increase ( $p=$ $0.00)$ was also found in the mean intake of vitamin A from 2003 (645 $\mu$ g or 107\% of RNI) to 2014 ( $870 \mu \mathrm{g}$ or $145 \%$ of RNI). On the whole, the mean intakes and RNI achievements for calcium, iron, and vitamin A have all showed increasing trends between 2003 and 2014 among the male, female, urban and rural populations.

The mean intake of vitamin $\mathrm{C}$ was slightly higher (75 $\mathrm{mg}$ or $107 \%$ of RNI) in 2014 than in 2003 (72 $\mathrm{mg}$ or 103\% of RNI). On the other hand, there was a decrease $(p=0.13)$ in the mean intake of thiamine from $2003(0.93 \mathrm{mg}$ or $81 \%$ RNI) to 2014 (0.90 $\mathrm{mg}$ or $78 \% \mathrm{RNI})$. When the respondents were categorised according to strata and gender, the mean intake and RNI achievement of vitamin C showed no significant changes from 2003 to 2014.

On average, Malaysian adults consumed less sodium in 2014 (2973 mg mean sodium intake) than they did in 2003 (3260 mg mean sodium intake). A decrease in sodium intake was also found when respondents were categorised according to gender and strata. However, the dietary intake of sodium among Malaysian adults was still almost double of the amount recommended by WHO (2012) and RNI 2017. Using the sodium intake level of $<2000 \mathrm{mg} /$ day (recommended for optimal blood pressure) as a guideline, only one-fifth of the Malaysian population had fulfilled this requirement in 2003 whereas in 2014, this number had increased to one-third. In the same vein, only onetenth of the Malaysian population had a daily sodium consumption of $\leq 1500 \mathrm{mg}$ in 2003. This figure had increased to almost one-fifth in 2014.

\section{DISCUSSION}

Our study augments the findings of previous studies concerning the nutrient intake in a population by accounting for the increase in overweight and obesity factors among the Malaysian population over a time period. Specifically, the prevalence of overweight and obesity had increased from $21 \%$ in year 1996 to $47.7 \%$ in year 2015 based on the National Health and Morbidity Surveys (IPH, 2015). In contrast, data from MANS surveys reported a median EI of 1,540 kcal per day in 2003 (Mirnalini et al., 2008) which decreased slightly to $1,466 \mathrm{kcal}$ per day in 2014 (IPH, 2014a). A possible reason for the discordance between the trends in diet and disease or disease risk factor in the population may be due to the analysis of data on the total survey population, without accounting for mis-reporting.

The presence of under- and overreporting, however, was highlighted. Macdiarmid and Blundell (1998) in their review from previous surveys concluded that under-reporting in large nutritional surveys ranged from $18-54 \%$ of the whole sample, but could be as high as $70 \%$ in particular subgroups. In our case, the percentage of energy under-reporters in the MANS was $54 \%$ in 2003 and $61 \%$ in 2014. The detailed characteristics of under-reporting of EI in MANS have been described elsewhere (Ahmad Ali et al., 2019). The previous reported daily EI of Malaysian adults ranged from 1500-2700 kcal (Chee et al., 1997; Lee, Norimah \& Ismail, 2010; Mirnalini 
et al., 2008; Sharif et al., 2016). After excluding the under- and over-reporting of EI, our analyses suggest that mean EI was around $2000 \mathrm{kcal}$ per day, a figure which meets the recommended intake for the Malaysian adult population.

Comparing the time periods 2003 and 2014, generally desirable changes in intake were found for almost all nutrients. Similar changes were observed in gender and strata groups. The average EI was satisfactory. The proportion of energy derived from macronutrients was within the dietary guidelines except for fat, which slightly exceeded for a healthy diet recommended by RNI Malaysia (NCCFN, 2017).

The accelerated pace of industrialisation and urbanisation of the recent years has generated marked changes in lifestyles, occupational patterns and dietary habits amongst Malaysians (Ismail, 2002; Sheng et al., 2008) such that large numbers of the urban population habitually eat out (Ali \& Abdullah, 2012). In both rural and urban areas, eating habits have shifted from traditional diets to the convenience of prepared and processed meals. The traditional diet is being replaced by diets higher in fats, salts and animal products and often with lower intakes of fresh fruits and vegetables (Soon \& Tee, 2014). As Malaysia rapidly proceeds towards a developed economy status, the population's lifestyle will continue to change. The escalation of nutritionrelated chronic degenerative diseases, once an urban phenomenon, has now spread to the rural population at an alarming rate (Ismail, 2002).

As shown earlier, only calcium intake did not meet RNI 2017. Asian populations, in general, have been reported to be calcium deficient, as evidenced by mean calcium intakes in Vietnam, Japan and Korea of approximately $500 \mathrm{mg} /$ day or less (Danh Tuyen et al., 2016; Ohta, Uenishi \& Shiraki, 2016). This could be due to the Asian diet, including Malaysian, and may be one of the barriers to achieving an increase in calcium intake. According to Singh et al. (2015), calcium intake was highly positively correlated with milk consumption, with highest levels in Western and lowest levels in Eastern Sub-Saharan Africa. Across 21 world regions, Central Latin America was the region with highest milk intake. Milk consumption also exceeded three-quarters of a serving in Europe and Southern Sub-Saharan Africa. However, adults in East Asia and Oceania consumed the least milk, it being less than a quarter of a serving per day. In Malaysia, Norimah et al. (2008) found that food consumption patterns among Malaysian adults from MANS 2003 showed that the highest prevalence of daily consumption of full-cream milk was only $24 \%$ and this occurred among older, predominantly female adults, aged 50-59 years, whereas those aged 18-19 years had the lowest prevalence of daily consumption at only $15 \%$.

Sodium intake has been a major concern with regard to the prevention of hypertension, and other related noncommunicable diseases in Malaysia. Regular nationwide health campaigns and health education could be a contributing factor in the significant decrease in sodium intake over the two survey periods. While the mean daily sodium intake in 2014 was significantly lower than that in 2003 , it is still $>1.5$ times higher than the recommended sodium intake limit of $2,000 \mathrm{mg}$ to control blood pressure (WHO, 2012) and two times higher than the minimum recommended sodium intake limit of $1500 \mathrm{mg}$ for Malaysia adults (NCCFN, 2017). These findings were lower than those obtained by assessing sodium intake using 24-hour urinary sodium excretion. It was reported that Malaysia adults aged 20-56 years excreted 142 mmol sodium per day which is equivalent to the intake of $3,429 \mathrm{mg}$ sodium per day, and this is 1.7 times higher than the recommended sodium intake limit of 2,000 mg (Rashidah et al., 2014). 
In comparison with the global surveys of 2010, the mean sodium intake was $3,950 \mathrm{mg}$ per day and nearly twice the WHO recommended limit of 2,000 mg per day. Intakes were highest in East Asia, Central Asia and Eastern Europe region (mean $>4200 \mathrm{mg} /$ day). However, contrary to the Asia regions, mean sodium intake in Malaysia was 3,570 $\mathrm{mg} /$ day and lower than the global mean sodium intake (Powles et al., 2013). A systematic review and meta-analyses on the effect of sodium intake in non-acutely ill adults showed that reduced sodium intake reduces blood pressure and lower sodium intake is also associated with a reduced risk of stroke and fatal coronary heart disease (Aburto et al., 2013).

The strength of this study was that it included a large representative sample of the Malaysian adult population, where the under-reporting and overreporting of EI in dietary assessment analysis were excluded. We acknowledge that the limitation of our study was the use of a single 24-hour diet recall as measurement of dietary intake as may not provide good estimates of intake compared to multiple 24-hour diet recalls.

\section{CONCLUSIONS}

Our findings have shown that most changes in nutrient intakes have improved in accordance with Malaysian nutrient recommendations (NCCFN, 2017). There have been significant changes in sources of energy, calcium, iron, sodium and vitamin A over the study period. This study has also revealed areas of concern, namely, that the consumption of carbohydrate has declined while the intakes of protein and fat have increased. These trends are in tandem with increases in chronic disease risk factors in the country, namely obesity. The adequacy of protein from current RNI cut-off (NCCFN, 2017) is not consistent with RNI achievement and should be reviewed. There is considerable scientific evidence linking excessive dietary fat intake with various health problems such as cardiovascular diseases, cancer, elevated cholesterol levels and obesity.

The results of this study have highlighted important information. There is a need for the promotion of a healthy lifestyle, particularly in having a balanced diet among targeted Malaysian populations.

\section{Acknowledgement}

The authors would like to thank the Director General of Health Malaysia for his permission to publish this paper.

\section{Author's contributions}

$\mathrm{AAZ}$, wrote the manuscript with support and supervised from all authors; SMY and AINI, verified the analytical methods. All authors provided critical feedback, discussed the results and contributed to the final manuscript.

\section{Conflict of interest}

The authors declare that there is no conflict of interest.

\section{References}

Aburto NJ, Ziolkovska A, Hooper L, Elliott P, Cappuccio FP \& Meerpohl JJ (2013). Effect of lower sodium intake on health: systematic review and meta-analyses. Bmj 346:f1326. https://doi.org/10.1136/bmj.f1326.

Ahmad Ali Z, Norazmir MN, Safiah MY, Adriana Irawati NI, Tahir A \& Foo LH (2019). Underreporting of energy and nutrient intake is a persistent issue in the Malaysian Adult Nutrition Survey. Mal J Nutr 25(2):97-119.

Ali N \& Abdullah MZ (2012). The food consumption and eating behaviour of Malaysian urbanites. issues and concerns. Geografia Malays J of Soc Space 8(6): 157-165.

Axxya Systems (2014). Nutritionist Pro Diet Analysis. From https://nexgen 1. nutritionistpro.com/shop/product-detail/ nutritionist-pro-diet-analysis-software-13. [Retrieved November 1 2018]

Azmi MY, Junidah R, Siti Mariam A, Safiah MY, Fatimah S, Norimah AK, Poh BK, Kandiah M, Zalilah MS, Wan Abdul Manan WM, Siti Haslinda MD \& Tahir A (2009). Body mass index (BMI) of adults: Findings of the Malaysian Adult Nutrition Survey (MANS). Mal J Nutr 15(2):97-119. 
Baharudin A, Ahmad MH, Naidu BM, Hamzah NR, Zaki NAM, Zainuddin AA \& Nor NSM. (2017). Reliability, technical error of measurement and validity of height measurement using portable stadiometer. Pertanika J Sci Technol 25(3):675686.

Black AE (2000). Critical evaluation of energy intake using the Goldberg cut-off for energy intake: basal metabolic rate. A practical guide to its calculation, use and limitations. Int JObes 24(9):1119-1130. http://doi.org/10.1038/ sj.ijo.0801376.

Chee SS, Ismail MN, Ng KK, \& Zawiah H (1997). Food intake assessment of adults in rural and urban areas from four selected regions in Malaysia. Mal J Nutr 3:91-102.

Danh TUYEN L, Thi Thu HIEN V, Thanh BINH P \& Yamamoto S (2016). Calcium and Vitamin D Deficiency in Vietnamese: Recommendations for an Intervention Strategy. J Nutr Sci Vitaminol 62:1-5. https://doi.org/10.3177/jnsv.62.1.

Garriguet D (2008). Under-reporting of energy intake in the Canadian Community Health Survey. Ssc-Jsm 19(4):37-45.

Geeta A, Jamaiyah H, Safiza MN, Khor GL, Kee CC, Ahmad AZ, Suzana S, Rahmah R \& Faudzi A (2009). Reliability, technical error of measurements and validity of instruments for nutritional status assessment of adults in Malaysia. Sing Med J 50(10):1013-1018.

Goldberg GR, Black AE, Jebb SA, Cole TJ, Murgatroyd PR, Coward WA \& Prentice AM (1991). Critical evaluation of energy intake data using fundamental principles of energy physiology: 1. Derivation of cut-off limits to identify under-recording. Eur $J$ Clin Nutr 45(12):569-81.

IPH (2011). Album Makanan Malaysia. Institute for Public Health, Ministry of Health Malaysia.

IPH (2014a). National Health and Morbidity Survey 2014 : Malaysia Adult Nutrition Survey (MANS) : Vol. III : Food Consumption Statistics of Malaysia. Institute for Public Health, Ministry of Health Malaysia.

IPH (2014b). National Health and Morbidity Survey 2014 : Malaysian Adult Nutrition Survey (MANS) Vol. II: Survey Findings. Institute for Public Health, Ministry of Health Malaysia.

IPH (2014c). National Health and Morbidity Survey 2014: Malaysian Adult Nutrition Survey. Vol. I: Methodology and General Findings. Institute for Public Health, Ministry of Health Malaysia.

IPH (2015). National Health and Morbidity Survey 2015 (NHMS 2015). Vol. II: Non-Communicable Diseases, Risk Factors and Other Health Problems. Institute for Public Health, Ministry of Health Malaysia.
Ismail MN (2002). The nutrition and health transition in Malaysia. Public Health Nutr 5(1a):191-195. PHN2001293.

https://doi.org/10.1079/

Ismail MN, Chee S, Roslee R \& Zawiah H (1998). Predictive equations for the estimation of basal metabolic rate in Malaysian adults. Mal J Nutr 4(1):73-80.

Klesges RC, Eck LH \& Ray JW (1995). Who underreports dietary intake in a dietary recall? Evidence from the Second National Health and Nutrition Examination Survey. $J$ Consult Clin Psychol, 63(3):438-444. https://doi. org/10.1037/0022-006X.63.3.438

Lee CL, Norimah AK \& Ismail MN (2010). Association of energy intake and macronutrient composition with overweight and obesity in Malay women from Klang Valley. Mal $J$ Nutr 16(2):251-260.

Macdiarmid J \& Blundell J (1998). Assessing dietary intake: Who, what and why of underreporting. Nutr Res Rev 11(02):231. https:// doi.org/10.1079/NRR19980017.

Mackerras D \& Rutishauser I (2005). 24-Hour National Dietary Survey Data: How Do We Interpret Them Most Effectively? Public Health Nutr 8(6):657-665. https://doi.org/10.1079/ PHN2005720.

Manan WAWM, Firdaus NI, Safiah MY, Haslinda SMD, Poh BK, Norimah AK, Azmi MY, Tahir A, Mirnalini K, Zalilah MS, Fatimah S, Noorazlin MN \& Fasiah W (2012). Meal patterns of Malaysian adults: Findings from the Malaysian Adults Nutrition Survey (MANS). Mal J Nutr 18(2):221-230.

MOH Malaysia (2002). Album Saiz Sajian Makanan Malaysia. Kajian Pengambilan Makanan Malaysia. Ministry of Health Malaysia.

MOH Malaysia (2006). Food consumption statistics of Malaysia 2003. Ministry of Health Malaysia.

MOH Malaysia (2008a). Malaysian Adult Nutrition Survey 2003: Dietary supplement use among adults age 18 to 59 years. Ministry of Health Malaysia.

MOH Malaysia (2008b). Malaysian Adult Nutrition Survey 2003: General Findings. Ministry of Health, Malaysia.

Mirnalini K, Zalilah MS, Safiah MY, Tahir A, Siti Haslinda MD, Siti Rohana D, Khairul Zarina MY, Mohd Hasyami S \& Normah H (2008). Energy and nutrient intakes: Findings from the Malaysian Adult Nutrition Survey (MANS). Mal $J$ Nutr 14(1):1-24. 
NCCFN (2017). Recommended Nutrient Intakes for Malaysia. National Coordinating Committee on Food and Nutrition, Ministry of Health Malaysia, Kuala Lumpur. From http://nutrition.moh. gov.my/wp-content/uploads / 2017 /05/FABuku-RNI.pdf. [Retrieved January 1 2018]

Norimah AK, Safiah M, Jamal K, Siti H, Zuhaida H, Rohida S, Fatimah S, Siti N, Poh BK, Kandiah M, Zalilah MS, Wan Manan WM, Fatimah S \& Azmi MY (2008). Food consumption patterns: Findings from the Malaysian Adult Nutrition Survey (MANS). Mal J Nutr 14(1):25-39.

Ohta H, Uenishi K \& Shiraki M (2016). Recent nutritional trends of calcium and vitamin D in East Asia. Osteoporos Sarcopenia 2(4):208-213. https://doi.org/10.1016/j.afos.2016.08.002.

Poh BK, Safiah MY, Tahir A, Siti Haslinda MD, Siti Norazlin N, Norimah AK, Wan Manan WM, Mirnalini K, Zalilah MS, Azmi MY \& Fatimah S (2010). Physical activity pattern and energy expenditure of Malaysian adults: Findings from the Malaysian adult Nutrition survey (MANS). Mal J Nutr 16(1):13-37.

Powles J, Fahimi S, Micha R, Khatibzadeh S, Shi P, Ezzati M, Engell RE, Lim SS, Danaei G \& Mozaffarian D (2013). Global, regional and national sodium intakes in 1990 and 2010: a systematic analysis of $24 \mathrm{~h}$ urinary sodium excretion and dietary surveys worldwide. BMJ Open 3(12):e003733. https://doi. org/10.1136/bmjopen-2013-003733.

Rashidah A, Yeo P, Noor Ani A, Muhammad Fadhli M, Tahir A, Feisul Idzwan M, Ahmad Ahli Z, Suhaila AG, Azli B, Viola M, Zainal AO, Ruhaya S \& Madihah M (2014). Sodium intake among normotensive health staff assessed by 24-hour urinary excretion: a cross-sectional study. Mal J Nutr 20(3):317-326.

Sahathevan S, Se CH, Ng SH, Chinna K, Harvinder GS, Chee WSS, Goh BL, Gafor HA, Bavanandan S, Ahmad G \& Karupaiah T (2015). Assessing protein energy wasting in a Malaysian haemodialysis population using self-reported appetite rating: a cross-sectional study. $B M C$ Nephrol 16(1):99. https://doi.org/10.1186/ s12882-015-0073-x.
Sandström B (2001). A framework for food-based dietary guidelines in the European Union. Public Health Nutr 4:293-305.

Sharif R, Wen LS \& Rajikan R (2016). Nutritional and physical activity status among adults living in low-cost housing area in Selangor. Jurnal Sains Kesihatan Malaysia 14(2):79-88.

Sheng TY, Shamsudin MN, Mohamed Z, Abdullah AM \& Radam A (2008). Complete demand systems of food in Malaysia. AGRICECON 54(10):467-475. https://doi.org/10.1021/ Je100666v.

Singh GM, Micha R, Khatibzadeh S, Shi P, Lim S, Andrews KG, Engell RE, Ezzati M \& Mozzafarian D (2015). Global, regional, and national consumption of sugar-sweetened beverages, fruit juices, and milk: A systematic assessment of beverage intake in 187 countries. PLoS ONE 10(8):1-20. https://doi.org/10.1371/journal. pone. 0124845 .

Soon JM \& Tee ES (2014). Changing trends in dietary pattern and implications to food and nutrition security in Association of Southeast Asian Nations (ASEAN). IJNFS 3(4):259-269. https://doi.org/10.11648/j. ijnfs.20140304.15.

Tee ES, Ismail MN, Nasir MA \& Khatijah I (1997). Nutrient Composition of Malaysian Foods. 4th Ed. Malaysian Food Composition Database Programme. Institute for Medical Research, Kuala Lumpur.

WHO (2012). Guideline: Sodium intake for adults and children. World Health Organization, Geneva. 